Dicle University Journal of Engineering (DUJE)

Araştırma Makalesi / Research Article

\title{
Ateş Böceği Algoritması Tabanlı PI Denetleyici Kullanarak Üç Fazlı Vienna Doğrultucunun Dinamik Performansının İncelenmesi
}

\author{
Dynamic Performance Investigation of Three Phase Vienna Rectifier using PI \\ Controller based on Firefly Algorithm \\ Ö. Fatih Keçecioğlu 1*, Hakan Açıkgöz ${ }^{2}$ \\ ${ }^{1}$ Kahramanmaraş Sütçü İmam Üniversitesi, Elektrik Elektronik Mühendisliği Bölümü, Kahramanmaraş, fkececioglu@ksu.edu.tr \\ ${ }^{2}$ Gaziantep İslam Bilim ve Teknoloji Üniversitesi, Elektrik Elektronik Mühendisliği Bölümü, Gaziantep, hakan.acikgoz@gibtu.edu.tr
}

\begin{tabular}{l} 
MAKALE BİLGİLERİ \\
\hline Makale geçmişi: \\
Geliş: 5 Mart 2020 \\
Düzeltme: 25 Haziran 2020 \\
Kabul: 11 Temmuz 2020 \\
\hline Anahtar kelimeler: \\
Vienna Doğrultucu, Ateş Böceği \\
Algoritması, PI Denetleyici
\end{tabular}

\section{ÖZET}

Bu çalışmada, üç fazlı Vienna doğrultucunun DA-Bara geriliminin denetimi için metasezgisel algoritmalardan biri olan Ateş Böceği Algoritması (ABA) tabanlı bir PI denetleyici yapısı önerilmiştir. ABA-PI adı verilen önerilen denetleyici yapısı içerisindeki PI denetleyicinin kazanç katsayıları ABA ile belirlenmiștir. ABA-PI denetleyicinin giriş referansı, giriş gerilimi ve yük değişimlerine karşı dinamik performansını incelemek için Matlab/Simulink ortamında kullanılarak benzetim çalıșmaları yapılmıștır. Yapılan benzetim çalıșmaları sonucunda önerilen ABAPI denetleyicinin tüm benzetim koşulları altında klasik PI denetleyiciye göre daha başarılı olduğu doğrulanmıştır.

Doi: $10.24012 /$ dumf.699156

\begin{tabular}{ll}
\hline ARTICLE INFO & ABSTRACT \\
Article history: & $\begin{array}{l}\text { In this study, a PI controller structure based on Firefly Algorithm (FA), which is one of the metaheuristic } \\
\text { algorithms is proposed for the control of the DC-Bus voltage of the three-phase Vienna rectifier. The gain }\end{array}$ \\
$\begin{array}{l}\text { coefficients of the PI controller within the proposed controller structure that is called FA-PI are determined by FA. } \\
\text { Received: } 5 \text { May } 2020\end{array}$ & $\begin{array}{l}\text { In order to verify the dynamic performance of the proposed controller against input reference, input voltage, and } \\
\text { load changes, simulation studies have been carried out under Matlab/Simulink environment. As a result of the } \\
\text { Accepted: 11 July 2020 }\end{array}$ simulation studies, it is confirmed that the proposed FA-PI controller is more successful than the classical PI \\
controller under all simulation conditions.
\end{tabular}

Vienna Rectifier, Firefly

Algorithm, PI Controller

\footnotetext{
* Sorumlu yazar / Correspondence

Ö. Fatih KEÇECIOĞLU

$\triangle$ fkececioglu@ksu.edu.tr
} 


\section{Giriș}

Günümüzde, birçok sistem güç elektroniği dönüştürücüleri aracılığıyla şebekeye bağlanmaktadır. Özellikle, üç fazlı AA-DA doğrultucu sistemleri enerji endüstrisinde çok yaygın olarak kullanılmaktadır. Bununla birlikte bu doğrultucular elektrikli araç şarjı, batarya şarj sistemleri, yenilenebilir enerji sistemleri gibi gelişmekte olan uygulamalarda performansın artırılması için önemli ölçüde katkı sağlamaktadır. Geleneksel iki seviyeli altı anahtarlı yükselten doğrultucular uygulamalarda yoğun olarak kullanılsa da bu doğrultucular harmonikli giriş akımı ve düşük güç faktörü gibi dezavantajlara sahip ve şebekede güç kalitesi sorunlarına neden olmaktadır [1]. Doğrultucular sahip olduğu bu dezavantajları gidermek için araştırmacılar, güç faktörü düzeltmeli, darbe genişlik modülasyonlu ve çok seviyeli doğrultucular gibi çeşitli doğrultucu devre yapılarını geliştirmişlerdir [2-5]. Çok seviyeli doğrultucular, düşük anahtarlama gerilimi ve stresi, yüksek verimlilik gibi üstünlükleri nedeniyle uygulamalarda tercih edilir hale gelmiştir [6-8].

Çok seviyeli doğrultucu yapıları içerisinde yer alan Vienna doğrultucu yapısı, telekomünikasyon sistemlerinin güç kaynaklarında kullanılmak üzere geliștirilmiștir [9]. Vienna doğrultucular yüksek verimlilik ve güç yoğunluğu, yüksek güvenilirlik, azaltılmış anahtarlama elemanı sayısı ve birim güç faktöründe çalıșma özellikleri sayesinde elektrikli araç batarya şarj sistemleri, esnek AA iletim sistemi cihazları ve rüzgar enerjisi dönüşüm sistemlerinde kullanılmaktadır [10-12].

Metasezgisel optimizasyon algoritmaları günümüzde mühendislik alanında birçok problemin çözümü için kullanılmaktadır. Ateş böceklerinin davranışlarından esinlenerek literatüre katılmıştır [13]. Literatürde ABA ile yapılan çalışmalar incelendiğinde, ABA'nın basit hesaplama adımı ve daha hızl yakınsama gibi avantajlarından dolayı ABA'nın yapay arı kolonisi, parçacık sürüsü optimizasyonu ve Bakteri Yiyecek Arama Optimizasyonu gibi diğer meta sezgisel algoritmalara karşı üstünlüğü literatürde bildirilmiştir [14-16]. Bununla birlikte bahsedilen bu üstünlüklerinden dolayı literatürde PID denetleyicilerin kazanç katsayılarını belirlemek için ABA son zamanlarda araștırmacılar tarafindan sıklıkla tercih edilir hale gelmiştir [17-19]. Vienna doğrultucu yapısı ve Ateş Böceği Algoritması (ABA) ile ilgili literatürde yapılan çalışmalar şu şekilde özetlenebilir:

Lai vd. [20], üç fazlı Vienna doğrultucu yapısı için yeni bir modelleme yapısını dq-eksen akımları için önermişlerdir. Bu yeni yöntem için detaylı matematiksel ifadeleri elde etmişler ve bu d-q eksenlerinin denetimleri için klasik PI denetleyiciler kullanmışlardır. Yazarlar, önerilen yöntemin doğruluğunu sağlamak için benzetim ve deneysel çalışmalar gerçekleştirmişlerdir. Reddy ve Ramasamy [10], yaptıkları çalışmada rüzgar enerji sistemine bağlı bir üç fazlı Vienna doğrultucunun denetimi için radyal tabanlı bir denetletici yapısı sunmuşlardır. Önerilen denetleyici yapısı üç katmandan oluşmaktadır. Önerilen denetleyici yapısına sahip olan Vienna doğrultucu için benzetim çalışmaları gerçekleştirilmiş ve performans değerlendirmeleri yapılmıştır. Aiello vd. [21], üç fazlı bir Vienna doğrultucu yapısı için FGPA tabanlı bir dinamik model gerçekleştirmişlerdir. Benzetim ve deneysel çalışmalar ile test çalışmaları yapmışlardır. Yu vd. [22], yaptıkları çalışmada gerilim sensörsüz üç fazlı Vienna doğrultucu için model öngörülü sanal ak1 denetimli set model geliştirmişlerdir. Çalışmada ilk olarak dq-eksen akımları arasındaki sanal akıların ilişkileri incelenmiştir. Daha sonra ise aktif ve reaktif güç denklemlerinden faydalanarak referans sanal akı hesaplanmış ve nötr nokta gerilimini dengelemek için ön vektör seçimi yapılmıştır. Benzetim ve deneysel çalışmalar ile önerilen yöntemin doğruluğu sağlamışlardır. Li vd. [23], Vienna doğrultucu yapısı için çift çevrime sahip olan melez bir denetim şeması önermişlerdir. Çalışmada, PI denetleyici, doğrultucu yapısının DA-barasını ve reaktif güç denetimi için tercih edilirken giriş akımları ile nötr nokta gerilim denetiminde model öngörülü denetim yöntemi uygulanmıştır. Yazarlar, bu yöntemin başarımını doğrulamak için deneysel çalışmalar gerçekleştirmişlerdir. Kedjar vd. [24], Vienna doğrultucu yapısı ile reaktif güç kompanzasyonu yeteneğine sahip ve harmonikleri azaltacak bir sistem tasarlamışlardır. Çalışmada, bu sistem için detaylı bir teorik çalışma gerçekleştirilmiştir. Daha sonra Doğrusal Kuadratik Regülatör denetleyici yapısına İntegral eklenerek daha dayanıklı bir 
denetleyici elde edilmiştir. Önerilen sistemin performansı deneysel çalışmalar yapılarak doğrulanmıștır. Aissa vd. [25], üç fazlı Vienna doğrultucu için bulanık mantık tabanlı bir akıllı PI denetleyici yapısı önermişlerdir. Önerilen denetleyici yapısı ile sabit DA-bara gerilimin elde edilmesi amaçlanmaktadır. Yazarlar ilk olarak benzetim çalışmaları yaparak klasik PI denetleyici ile önerdikleri denetleyici yapısını farklı senaryolar ile karşılaştırmışlardır. Daha sonra Vienna doğrultucu yapısı için deneysel kurulum gerçekleştirilmiş ve elde edilen sonuçlar değerlendirilmiştir. Dang vd. [26], yaptıkları çalışmada Vienna doğrultucu yapısı için yeni bir model öngörülü denetim şeması önermişlerdir. İlk olarak Vienna doğrultucu yapısının çıkışında bulunan DA-bara gerilimleri her örnekleme periyodu aralığındaki tüm anahtarlama durumlarına göre tahmin edilmiştir. Nötr nokta gerilimindeki dengesizlik ile baş etmek için yeni bir maliyet fonksiyonu geliştirilmiştir. $\mathrm{Bu}$ fonksiyon her bir hesaplamadan sonra güncellenmektedir. Deneysel çalışmalar ile önerilen denetim yönteminin performansı incelenmiştir.

Sundareswaran vd. [27], ateşböceği algoritmasını kullanarak kısmi gölgelenme koşulları altında fotovoltaik sistemler için bir maksimum güç noktası izleme yöntemi geliştirmişlerdir. Belkacem vd. [28] yaptıkları çalışmada çok seviyeli eviricilerde toplam harmonik bozulmayı en aza indirmek için ateşböceği algoritmasını kullanarak en iyi anahtarlama açılarını bulan bir yöntem önermişlerdir. Demirdelen [29], çalışmasında ateş böceği algoritması yöntemi kullanılarak kuru tip transformatörü maksimum verim elde edilebilecek şekilde yeniden tasarlamıștır. Merugumalla ve Navuri [30], yaptıkları çalışmada firçasız doğru akım motor sürücüsünün denetimi için ateşböceği algoritması tabanlı PID denetleyici tasarlamıș ve benzetimini gerçekleştirmişlerdir. Yazarlar benzetim sonuçlarını kararlı durum hatası, yükselme süresi, oturma süresi ve aşım gibi zaman domeni performans kriterlerini kullanarak analiz etmiștir.

Vienna doğrultucu yapısı ve ABA ile ilgili yapılan çalışmalar incelendiğinde Vienna doğrultucunun denetimi için ABA tabanlı bir denetleyici yapısı daha önce geliştirilmemiştir. Bu çalışmada üç fazlı Vienna doğrultucunun DABara geriliminin denetimi ABA tabanlı bir PI denetleyici yapısı önerilmiştir.

$\mathrm{Bu}$ makale şu şekilde düzenlenmiştir: Vienna doğrultucunun matematiksel modeli makalenin 2. bölümünde, ateş böceği algoritması makalenin 3 . Bölümünde, benzetim çalışmaları ve sonuçları ise makalenin 4. bölümünde verilmiştir.

\section{Vienna Doğrultucu Yapısının Matematiksel Modeli}

Üç fazlı Vienna doğrultucunun devre şeması Şekil 1'de verilmiştir. Şekilden de görüldüğü gibi Vienna doğrultucu yapıs1; L tipi filtre, altı tane diyot, çift yönlü IGBT anahtarlar ve DA-bara kapasitörlerinden oluşmaktadır. Şekil 1'de kullanılan IGBT'lerin denetlenmesi ile giriş akımının sinüzoidal olması ve sabit çıkış geriliminin elde edilmesinin sağlanması amaçlanmaktadır. Üç fazlı Vienna doğrultucuya uygulanan gerilimler IGBT anahtarların iletimde ya da kesimde kalma durumlarına ve șebeke akımının polaritesine bağlıdır. 


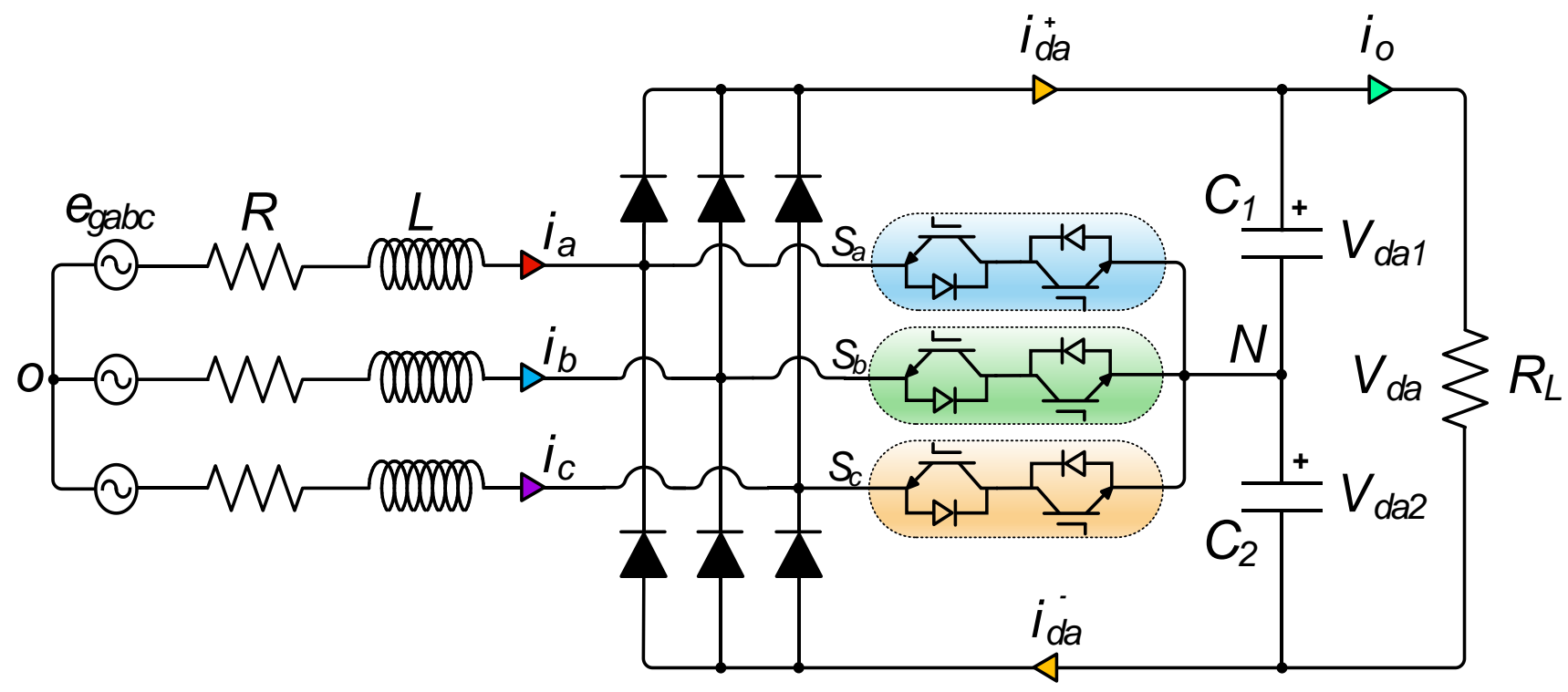

Şekil 1. Üç fazlı Vienna doğrultucu yapısı

Şekil 1'deki doğrultucu devresine göre Vienna doğrultucunun giriş kısmındaki gerilimler aşağıdaki gibi yazılabilir.

$$
\begin{gathered}
e_{g a}=E \sin (\omega t) \\
e_{g b}=E \sin \left(\omega t-120^{\circ}\right) \\
e_{g c}=E \sin \left(\omega t+120^{\circ}\right)
\end{gathered}
$$

Burada, E ve $\omega$ sirasıyla gerilimin genliği ve açısal frekansıdır.

$$
\begin{aligned}
& L \frac{d i_{a}}{d t}=e_{g a}-R i_{a}-u_{a N} \\
& L \frac{d i_{b}}{d t}=e_{g b}-R i_{b}-u_{b N} \\
& L \frac{d i_{c}}{d t}=e_{g c}-R i_{c}-u_{c N}
\end{aligned}
$$

Burada, L giriş kısmında kullanılan filtre elemanıdır. e eabc ve $i_{a b c}$ ise sırasıyla şebeke gerilimlerini ve faz akımlarını simgelemektedir. Vienna doğrultucunun modellenmesini daha basite indirmek için anahtarlama durumları ile daha kompakt bir eşitlik aşağıdaki gibi ifade edilebilir.

$$
\begin{aligned}
& u_{a N}=K_{a} \frac{v_{d a}}{2} \\
& u_{b N}=K_{b} \frac{v_{d a}}{2} \\
& u_{c N}=K_{c} \frac{v_{d a}}{2}
\end{aligned}
$$

Burada, $v_{d a}$ çıkış kısmındaki DA-bara gerilimin temsil etmektedir. $K_{i} \quad\{i=a, b, c\}$ aşağıdaki gibi verilebilir.

$$
\begin{aligned}
& K_{a}=\left(1-S_{a}\right) \operatorname{sgn}\left(i_{a}\right) \\
& K_{b}=\left(1-S_{b}\right) \operatorname{sgn}\left(i_{b}\right) \\
& K_{c}=\left(1-S_{c}\right) \operatorname{sgn}\left(i_{c}\right)
\end{aligned}
$$

Yukarıda verilen eşitlikler kullanılarak üç fazlı gerilim dalga şekillerinin $-\pi / 6$ ile $\pi / 6$ bölgesinde kalan kısmı için anahtarlama durumları Tablo 1'de verilmiştir. Üç fazlı değișkenlerin dqeksenlerinde değerlerine dönüșümü için park dönüşümü yardımıyla gerçekleștirilebilir. $\mathrm{Bu}$ dönüşümlerdeki kenetlenme etkisi nedeniyle denetleyici tasarımı zorlaşmaktadır. Denklem 2'de verilen eşit, Park dönüşümü yardımıyla dqeksenlerine aşağıdaki gibi dönüştürülebilir:

Tablo 1. Vienna doğrultucu için anahtarlama durumlarl

\begin{tabular}{|c|c|c|c|c|c|}
\hline $\mathbf{S}_{1}$ & $\mathbf{S}_{2}$ & $\mathbf{S}_{3}$ & $\mathbf{U}_{\mathbf{a N}}$ & $\mathbf{U}_{\mathbf{b N}}$ & $\mathbf{U}_{\mathbf{c N}}$ \\
\hline $\mathbf{0}$ & 0 & 0 & $\mathrm{~V}_{\mathrm{da}} / 2$ & $-\mathrm{V}_{\mathrm{da}} / 2$ & $-\mathrm{V}_{\mathrm{da}} / 2$ \\
\hline $\mathbf{0}$ & 0 & 1 & $\mathrm{~V}_{\mathrm{da}} / 2$ & $-\mathrm{V}_{\mathrm{da}} / 2$ & 0 \\
\hline $\mathbf{0}$ & 1 & 0 & $\mathrm{~V}_{\mathrm{da}} / 2$ & 0 & $-\mathrm{V}_{\mathrm{da}} / 2$ \\
\hline $\mathbf{0}$ & 1 & 1 & $\mathrm{~V}_{\mathrm{da}} / 2$ & 0 & 0 \\
\hline $\mathbf{1}$ & 0 & 0 & 0 & $-\mathrm{V}_{\mathrm{da}} / 2$ & $-\mathrm{V}_{\mathrm{da}} / 2$ \\
\hline $\mathbf{1}$ & 0 & 1 & 0 & $-\mathrm{V}_{\mathrm{da}} / 2$ & 0 \\
\hline
\end{tabular}




\begin{tabular}{|c|c|c|c|c|c|}
\hline $\mathbf{1}$ & 1 & 0 & 0 & 0 & $-\mathrm{V}_{\mathrm{da}} / 2$ \\
\hline $\mathbf{1}$ & 1 & 1 & 0 & 0 & 0 \\
\hline
\end{tabular}

$$
\begin{aligned}
& L \frac{d i_{d}}{d t}=e_{d}-R i_{d}+\omega L i_{q}-u_{d} \\
& L \frac{d i_{q}}{d t}=e_{q}-R i_{q}-\omega L i_{d}-u_{q}
\end{aligned}
$$

Üç fazlı Vienna doğrultucunun DA-bara çıkışında kullanılan kapasitörler $\left(C_{1}\right.$ ve $\left.C_{2}\right)$ için dinamik eşitlikler de aşağıdaki gibi ifade edilebilir:

$$
\begin{gathered}
C_{1} \frac{d V_{d a 1}}{d t}=i_{d c}^{+}-i_{o} \\
C_{2} \frac{d V_{d a 2}}{d t}=i_{d c}^{-}-i_{o}
\end{gathered}
$$

$\mathrm{Bu}$ ifadede verilen $i_{d c}^{+}$ve $i_{d c}^{-}$; DA-baradan üzerinden geçen akımları $i_{o}$ ise yük akımıdır. $\mathrm{Bu}$ akımlar şu şekilde tanımlanabilir:

$$
\begin{aligned}
& i_{d c}^{+}=\sum_{i \in\{a, b, c\}}\left(1-S_{i}\right)\left[\frac{\operatorname{sgn}\left(i_{i}\right)+1}{2}\right] i_{i} \\
& i_{d c}^{-}=\sum_{i \in\{a, b, c\}}\left(1-S_{i}\right)\left[\frac{\operatorname{sgn}\left(i_{i}\right)+1}{2}\right] i_{i}
\end{aligned}
$$

Doğrultucu devresinin aktif (P) ve Reaktif güç (Q) eşitlikleri ise aşağıdaki denklemlerle elde edilebilir. Ayrıca, birim güç faktöründe çalışma için q-ekseni akımının değerinin sıfıra eşit olarak seçilmesi gerekmektedir ve denetiminin de yapılması oldukça önemlidir.

$$
\begin{gathered}
P=\frac{3\left(e_{d} i_{d}+e_{q} i_{q}\right)}{2} \\
Q=\frac{3\left(e_{q} i_{d}-e_{d} i_{q}\right)}{2}
\end{gathered}
$$

\section{Ateş Böceği Algoritması}

Ateş böceği algoritması (ABA), ateş böceklerinin davranışlarına ve parlaklıklarına dayalı metasezgisel bir optimizasyon yöntemidir. Yang [13] tarafından literatüre katılan ABA yönteminin aşağıda belirtilen üç temel varsayımı vardır. Bunlar:
- Tüm ateş böcekleri cinsiyetsiz kabul edilir cinsiyetlerine bakılmaksızın daha çekici ve daha parlak olana doğru hareket edilir.

- Bir ateş böceğinin çekiciliği, kendisi ve diğer ateş böcekleri arasındaki mesafeye bağlı olan parlaklığı ile ilgilidir. Bununla birlikte, havadaki $1 s ̧ 1 \mathrm{k}$ emilimi nedeniyle, mesafe arttıkça çekicilik azalır.

- Bir ateş böceğinin parlaklığı veya 1 şık yoğunluğu, verilen bir problemin amaç fonksiyonunun değeri ile belirlenir.

Ateş böceği algoritması matematiksel olarak, üç denklemle ifade edilebilir. Ateş böceklerinin çekicilik ( $\beta$ ) parametresi için şu ifade kullanılır:

$$
\beta(r)=\beta_{0} e\left(-\gamma r^{m}\right), \quad m \geq 1
$$

bu ifadede verilen $\beta_{0}$ parametresi $\mathrm{r}=0$ 'daki başlangıç çekiciliğidir. $r$ parametresi, iki ateş böceği arasındaki mesafedir. $\gamma, \quad 1 s ̧ 1 \mathrm{k}$ yoğunluğunun azaltılmasını kontrol eden bir soğurma katsayısıdır. $\mathrm{m}$ bir tamsayıdır. İki ateşböceğini, sırasıyla $\mathrm{x}_{\mathrm{i}}$ ve $\mathrm{x}_{\mathrm{j}}$ konumlarında kabul ederek ve iki ateşböceği algoritması arasındaki mesafe şu şekilde tanımlanabilir:

$$
r_{i j}=\left\|x_{i}-x_{j}\right\|=\sqrt{\sum_{k=1}^{d}\left(x_{i, k}-x_{j, k}\right)^{2}}
$$

burada $x_{i, k}$ ve $x_{j, k}$, $i$ ve $j$. ateşböceğinin uzamsal koordinatlarının $\mathrm{k}$. bileşenleridir $\mathrm{d}$ parametresi ise boyutların sayısıdır. Bir ateş böceğinin hareketi şu şekilde belirlenir:

$$
x_{i}=x_{i}+\beta_{0} e^{-\gamma r_{i j}^{2}}\left(x_{j}-x_{i}\right)+\alpha\left(\text { rand }-\frac{1}{2}\right)
$$

Burada, $\alpha \in[0,1]$ ve randn rastgele bir pertürbasyon değeridir. Bu ifade aynı zamanda bir ateş böceğinin hareketinin çekicilik ve rasgeleleştirmeden etkilendiğini açıkça belirtir. Genel olarak, küçük $\alpha$ değeri yerel noktaları aramayı, büyük $\alpha$ değeri ise global noktaları aramayı sağlar. Vienna doğrultucunun DA-Bara geriliminin denetimi için önerilen ABA-PI denetleyicinin kazanç katsayılarını bulmak için kullanılan ABA parametreleri Tablo 2'de verilmiştir. Tüm bu algoritma parametreleri yapılan kapsamlı simülasyon çalışmaları ile seçilmiştir. Ayrıca denetleyicinin kazanç katsayılarının ABA yardımı ile bulunması süreci 
akış şeması ile Şekil 2 üzerinde açıkça gösterilmiştir.

Tablo 2. ABA parametreleri

\begin{tabular}{|c|c|}
\hline Parametre & Değeri \\
\hline$\beta_{0}$ & 2 \\
\hline $\mathrm{m}$ & 2 \\
\hline$\gamma$ & 1 \\
\hline Popülasyon Sayıs1 & 10 \\
\hline Maksimum İterasyon Say1s1 & 20 \\
\hline
\end{tabular}

\section{Benzetim Çalışmaları}

$\mathrm{Bu}$ kısımda üç fazlı Vienna doğrultucu devresinin DA bara geriliminin denetiminde kullanılan ABA-PI denetleyicinin performansını doğrulamak için üç farklı senaryo oluşturulmuştur. Bu senaryolar Matlab/Simulink ortamı kullanılarak gerçeklenmiştir. Vienna doğrultucu yapısına ait benzetim modeli Şekil 3'te, benzetim çalışmasında kullanılan parametreler ise Tablo 3'de verilmiştir. Benzetim çalışmalarında kullanılan PI denetleyicinin başlangıç değerleri ilk olarak Ziegler-Nichols yöntemi ile belirlenmiş ve daha sonra denemeyanılma yöntemiyle ayarlanmıştır.

Tablo 3. Vienna Doğrultucu Yapısının Parametreleri

\begin{tabular}{|c|c|}
\hline Parametre & Değeri \\
\hline Giriş Gerilimi & $400 \mathrm{~V}$ \\
\hline DA Bara Gerilimi & $600 \mathrm{~V}$ \\
\hline Kapasitörler & $2000 \mu \mathrm{F}$ \\
\hline Hat Endüktansı ve İç Direnci & $0.3 \mathrm{mH} 0.1 \Omega$ \\
\hline Rezistif Yük & $40 \Omega$ \\
\hline Örnekleme Periyodu & $1 \mu \mathrm{s}$ \\
\hline
\end{tabular}

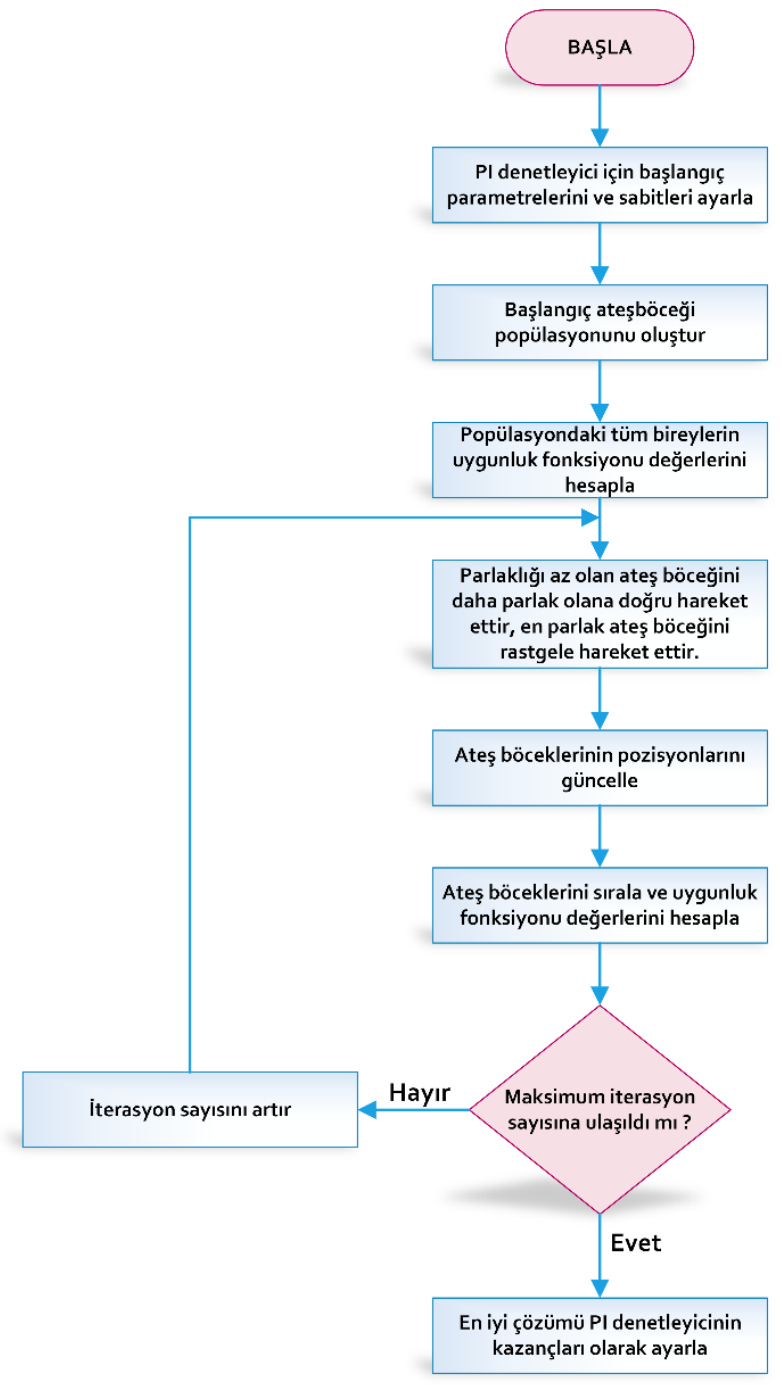

Şekil 2. Ateş böceği algoritması akış şeması 


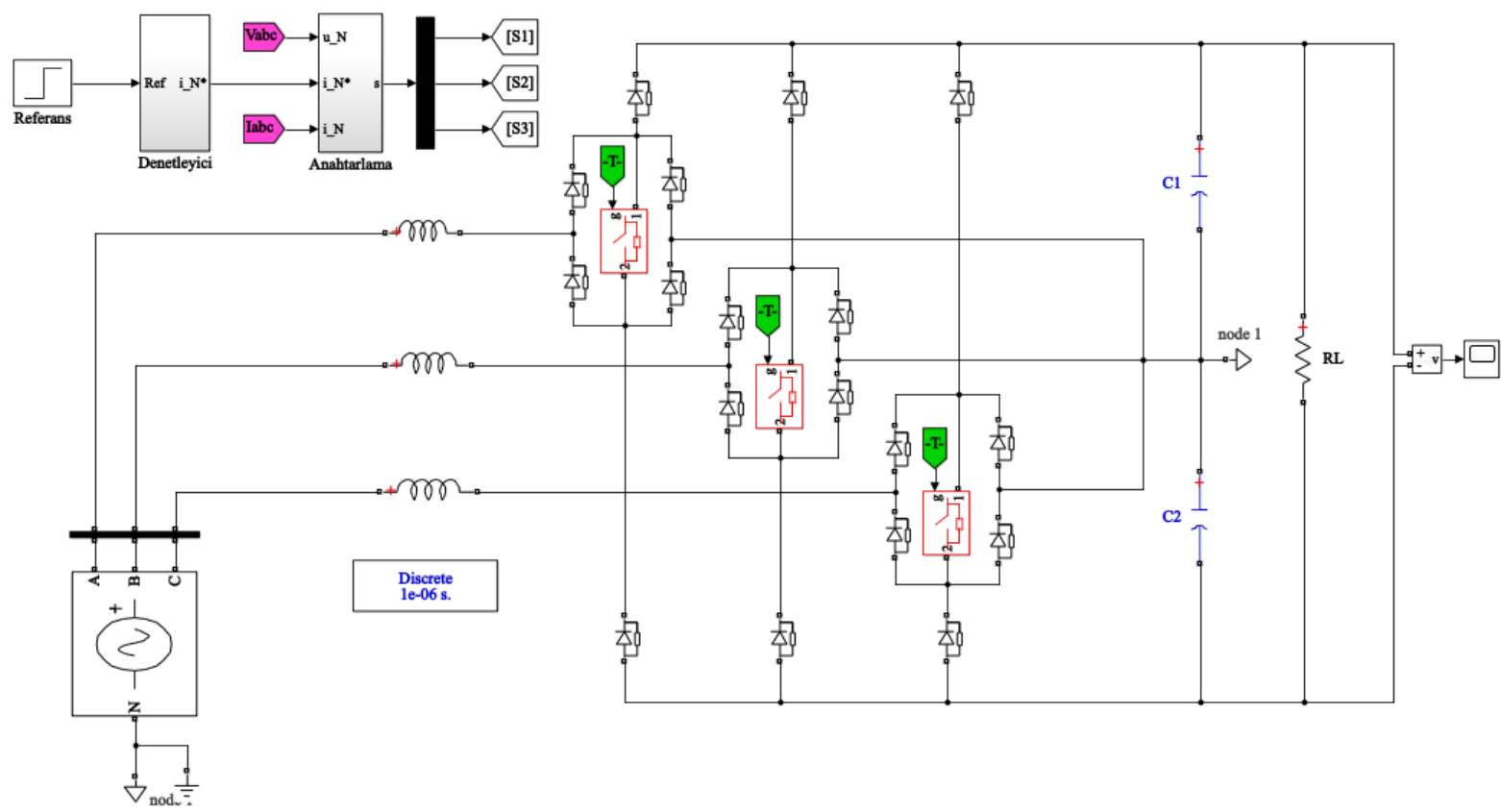

Şekil 3. Benzetim Modeli

\section{Senaryo-1: Referans DA-Bara Değişimi}

$\mathrm{Bu}$ senaryoda önerilen denetleyicinin giriş DA Bara gerilimi değişimine karşı referansı takip edebilme performansını incelemek için referans DA Bara gerilimi benzetim çalışmasının belirli bir zamanında 700 V'dan 750 V'a yükseltilmiştir. Aynı zamanda bu senaryo, sabit yük ve dengeli şebeke gerilimi koşulları altında gerçeklenmiştir. Denetlenen sistemi, dinamik performans kriterleri (yükselme zamanı, yerleşme zamanı ve aşım) açısından incelenmek için önerilen denetleyici yapısı ile klasik PI tipi denetleyicinin başarımları karşılaştırılmıştır. Bu senaryo için elde edilen benzetim sonuçları Şekil 4 üzerinde gösterilmiştir. Şekil 4 (a)'da görüldüğü üzere DA bara referans gerilimi benzetim çalışmasının 0.05 . saniyesinde $700 \mathrm{~V}$ değerinden $750 \mathrm{~V}$ değerine yükseltilmiştir. Denetleyicilerin referans
DA Bara gerilimi değişimine verdikleri cevaplar detaylı olarak sırasıyla Şekil 4 (b) ve (c)'de sunulmuştur. Önerilen ABA-PI denetleyici 5.2 $\mathrm{ms}$ sonra referans değerini yakalarken PI denetleyici ise $6 \mathrm{~ms}$ sonra referans1 takip edebilmiştir. ABA-PI ve klasik PI denetleyicilerin aşım cevapları ise sırasıyla $753 \mathrm{~V}$ ve 754.7 V olarak hesaplanmıştır. Şekil 4 (d)'de ise şebeke gerilim ve akımlarının A-fazı için dalga şekilleri verilmiştir. Bu şekil incelendiğinde akım ve gerilim arasında faz farkının bulunmadığı ve her iki denetleyicinin de Vienna doğrultucuyu birim güç faktöründe başarı ile çalıştırdığ 1 görülmektedir. Her iki denetleyici yapısı için başarım sonuçları incelendiğinde; ABA-PI denetleyicinin bu senaryoda tüm performans kriterleri bakımından klasik PI denetleyiciden daha başarılı olduğu açıkça görülmüştür. 

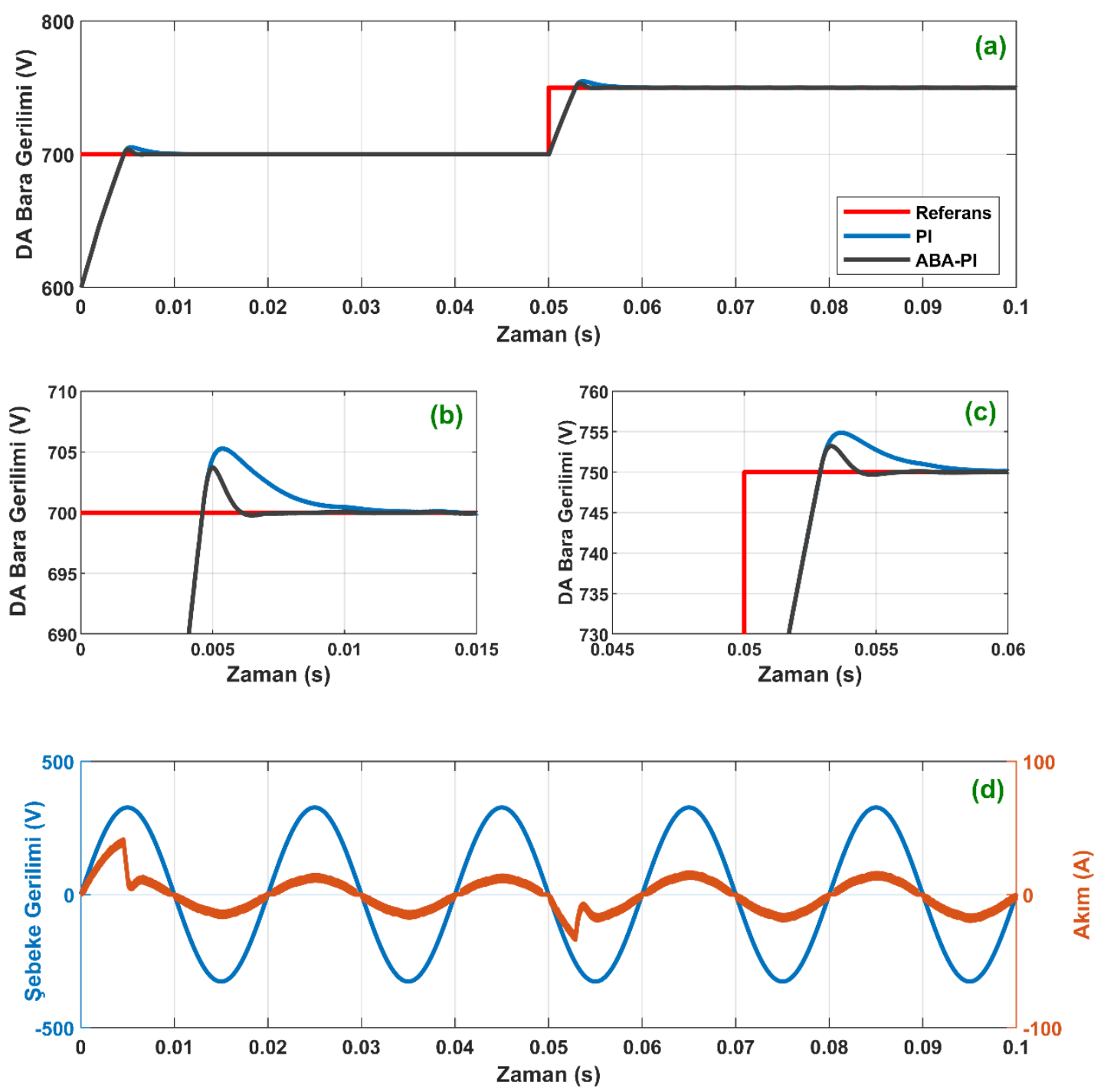

Şekil 4. Senaryo-1 için elde edilen benzetim sonuçları

\section{Senaryo-2: Gerilim Çökmesi Durumu}

$\mathrm{Bu}$ senaryoda Vienna doğrultucu için önerilen ABA-PI denetleyicinin performansı üç fazlı gerilim çökmesi koșulu altında incelenmiştir. $\mathrm{Bu}$ amaç için benzetim çalışmasının 0.04. saniyesinde başlayan ve iki periyot boyunca devam eden \%10'luk üç fazlı gerilim çökmesi olayı meydana getirilmiștir. Bu senaryodan elde edilen benzetim çalışmaları sonuçları Şekil 5'te gösterilmiştir. Şekil 5 (a-d)'de görüldüğü üzere gerilim çökmesi olayında DA bara geriliminin cevabı önerilen denetleyici için $699 \mathrm{~V}$ değerine, klasik PI denetleyicide ise $698 \mathrm{~V}$ değerine düşmektedir. Bu gerilim çökmesi olayı ortadan kaldırıldığında ise DA bara gerilimi cevapları sırasıyla $701.4 \mathrm{~V}$ ve $702.1 \mathrm{~V}$ olmuştur. Bu geçici durum karşısında şebeke akımı Şekil 5 (d)'de görüldüğü üzere DA bara gerilimini sabit tutmak için artmıştır. Benzetim çalışmasının sonuçları dikkatlice incelendiğinde önerilen ABA-PI denetleyicinin șebekede meydana gelebilecek bu tür olaylara karşı klasik PI denetleyiciden daha kararlı yapıda olduğu ve sistemin dinamik performansını iyileştirdiği bariz bir şekilde görülmektedir. 

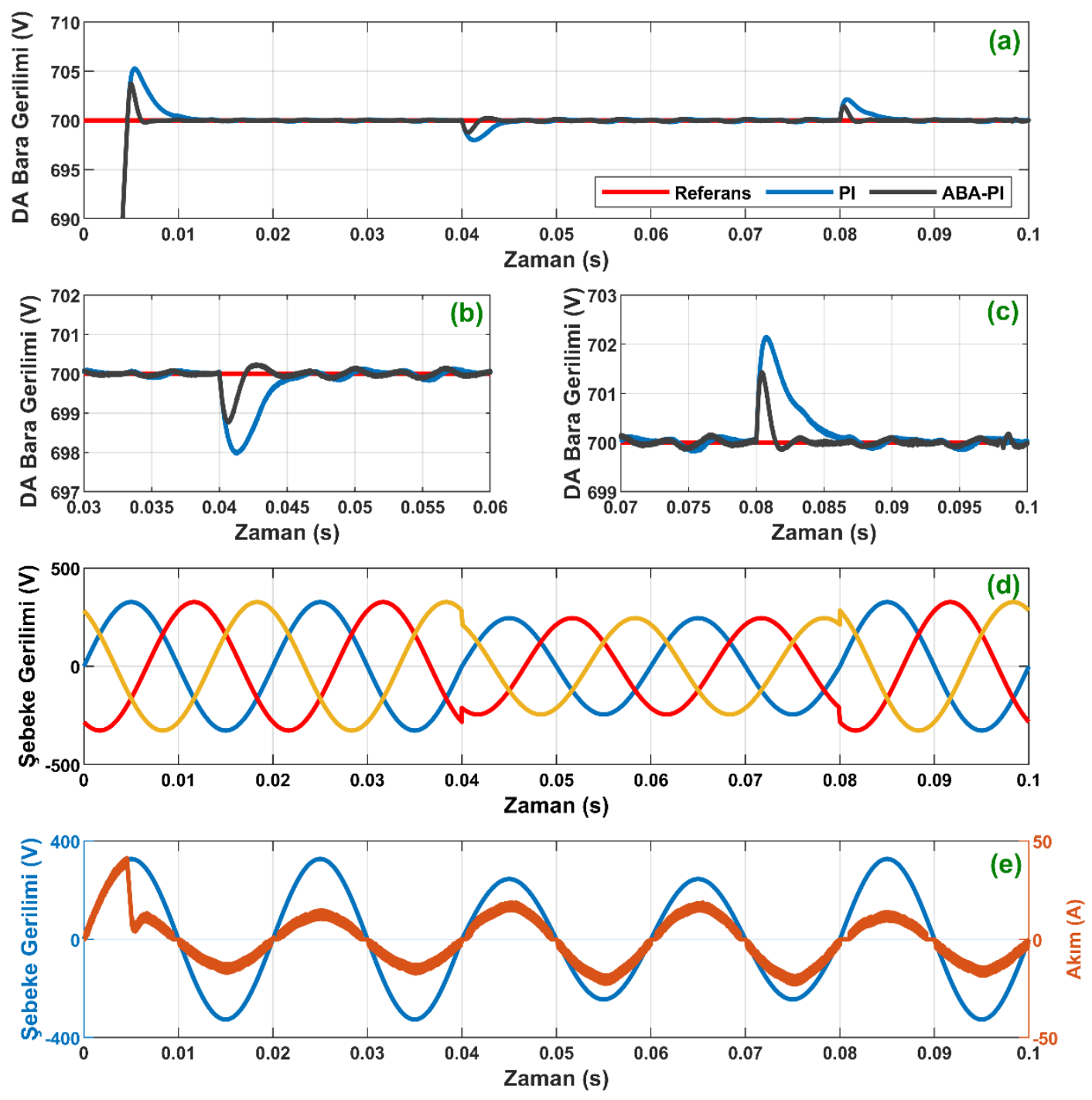

Şekil 5. Senaryo-2 için elde edilen benzetim sonuçları

\section{Senaryo-3: Ani Yük Değişimi}

Benzetim çalışmalarının bu senaryosunda Vienna doğrultucunun performansı yük değişimi altında her iki denetleyici yapısı için incelenmiștir. $\mathrm{Bu}$ senaryoda Vienna doğrultucunun DA bara gerilim değeri tüm benzetim süresi boyunca 700 $\mathrm{V}$ değerine ayarlanmıştır. Benzetim çalışmasından elde edilen sonuçlar Şekil 6 üzerinde sunulmuştur. Vienna doğrultucunun çıkışına bağlı olan rezistif yüklerin değeri 0.04 . saniyede $40 \Omega$ 'dan $20 \Omega$ 'a düşürülmüş ve daha sonra bu $20 \Omega$ 'luk yük değeri 0.06 . saniyede eski değerine getirilmiştir. ABA-PI ve PI denetleyicilerin bu yük değişimine karş1 verdikleri DA bara gerilim cevapları Şekil 6 (ac)'de gösterilmiștir. Önerilen denetleyicinin DA bara gerilim cevabı, bu yük değişiminde 698.4 V'a anlık olarak düşmüş ve çok hızlı bir şekilde toparlanarak $2 \mathrm{~ms}$ sonra referans DA bara gerilimini takip etmeyi başarmıştır. $\mathrm{Bu}$ yük değişimine karşı klasik PI denetleyicinin DA bara gerilim cevabı $700 \mathrm{~V}$ değerinden $697.2 \mathrm{~V}$ ' değerine düşmüș ve $7 \mathrm{~ms}$ sonra referans DA bara gerilimini yakalamıștır. Buradan, ABA ile PI denetleyicinin dinamik performansının \%71 
oranında iyileștirildiği ifade edilebilir. Șekil 6 (d)'de görüldüğü üzere yük değișimi koșulu altında şebeke geriliminde herhangi bir değişim meydana gelmemiștir. Bununla birlikte, Șekil 6 (e) incelendiğinde, yük değişimlerinde şebeke akımı ve gerilimi arasındaki faz farkı korunmuş olup Vienna doğrultucu birim güç faktöründe çalışmayı başarmıştır.
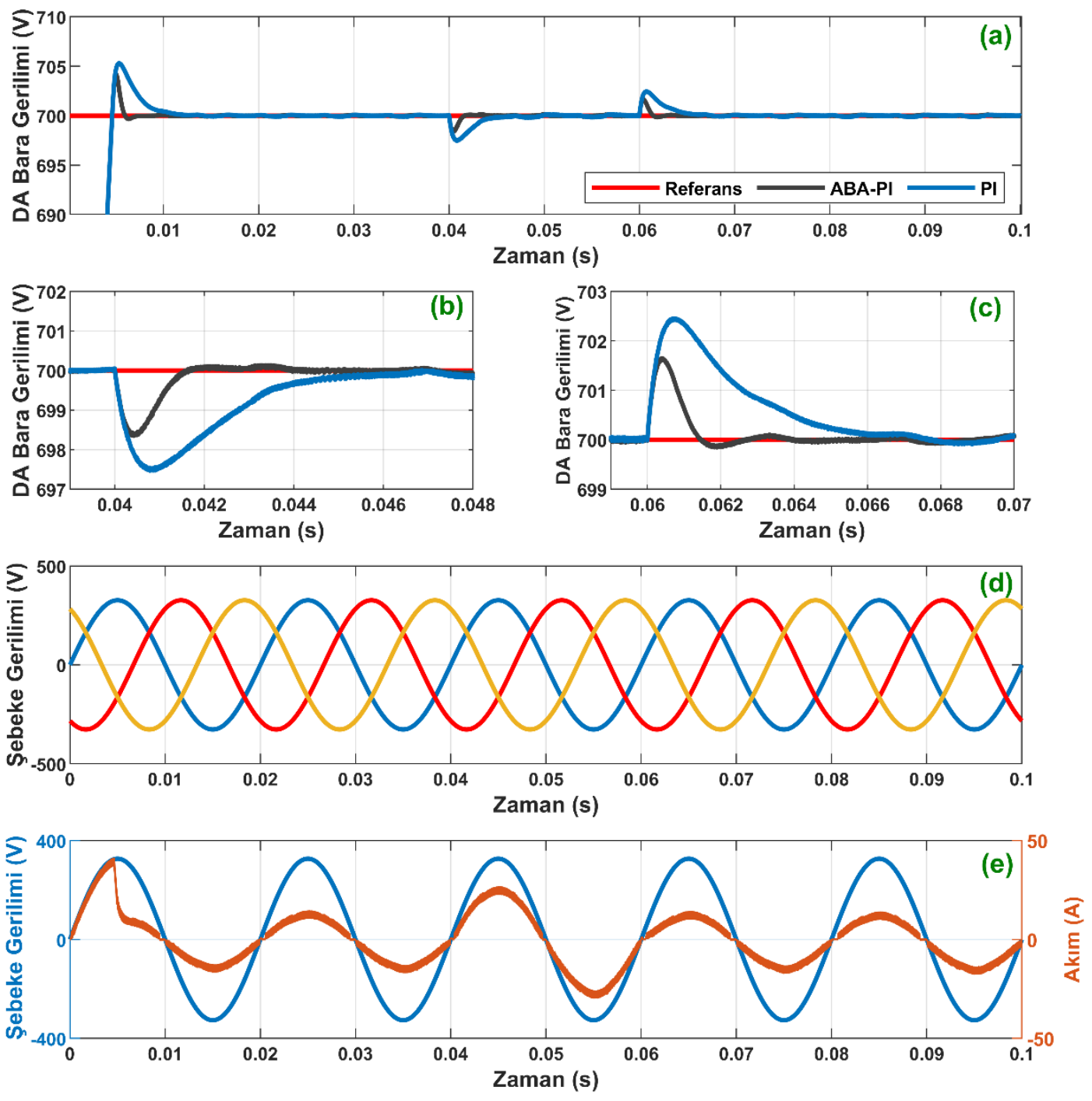

Şekil 6. Senaryo-3 için elde edilen benzetim sonuçları

\section{Sonuçlar}

$\mathrm{Bu}$ çalışmada, üç fazlı bir Vienna doğrultucu devresinin DA-bara geriliminin dinamik cevabını iyileştirmek için ABA-PI denetleyici yapısı önerilmiştir. Bilindiği gibi klasik PI denetleyicilerin kazanç parametrelerinin belirlenmesi için ya deneme-yanılma yöntemi ya da indirgenmiş matematiksel model yardımıyla oluşturulan transfer fonksiyonlarından faydalanılmaktadır. Bu yöntemlerin her ikisi de hem zaman almakta hem de denetlenecek olan sistemin doğru bir matematiksel modeline sahip olmadıkları için zayıf performanslara sahip olmaları istenilmeyen özelliklerindendir. $\mathrm{Bu}$ sorunların üstesinden gelmek için optimizasyon yöntemleri bir çözüm yolu olarak ortaya çıkmaktadır. $\mathrm{Bu}$ çalışmada, Ateş Böceği Algoritması (ABA) yardımıyla PI denetleyicinin kazanç parametrelerinin belirlenerek Vienna doğrultucu devresine uygulanması amaçlanmıştır. $\mathrm{Bu}$ amaç için ilk olarak Matlab/Simulink ortamında Vienna doğrultucu modeli tasarlanmıștır. Daha sonra ise ABA-PI ve PI denetleyicinin parametreleri belirlenmiștir. Her iki denetleyici aynı şartları altında üç senaryo üzerinden yerleşme zamanı, yükselme zamanı ve aşım açısından karşılaştırılmıştır. Tüm benzetim 
çalışmalarından elde edilen sonuçlara göre, ABAPI denetleyicinin klasik PI denetleyiciye göre performansının daha iyi olduğu anlaşılmıştır. Önerilen denetleyici yapısının kullanılması ile tüm sistemin performansının iyileştirilebileceği yapılan benzetim çalışmalarıyla da doğrulanmıştır.

\section{Kaynaklar}

[1] Bueno, E. J., C'obreces, S., Rodr'iguez, F. J., Hern'andez, A. Espinosa, F., (2008). Design of a back-to-back NPC converter interface for wind turbines with squirrel-cage induction generator, IEEE Trans. Energy Convers., 23, 3, 932-945.

[2] Baev, S., Shtessel, Y., Sheffield, M., (2008). Sliding Mode Control of a Unity Power Factor 3-Phase AC/DC Boost Converter, IEEE Southeast Conference, 491-496.

[3] Coteli, R., Acikgoz, H., Ucar, F., Dandil, B., (2017). Design and implementation of Type-2 fuzzy neural system controller for PWM rectifiers, International Journal of Hydrogen Energy, 42, 32, 20759-20771.

[4] Acikgoz, H., Kececioglu, O. F., Gani, A., Yildiz, C., Sekkeli, M., (2016). Improved control configuration of PWM rectifiers based on neuro-fuzzy controller, SpringerPlus, 5, 1, 1142.

[5] Rodriguez, J. R., Dixon, J. W., Espinoza, J. R., Pontt, J., Lezana, P., (2005). PWM regenerative rectifiers: state of the art, IEEE Transactions on Industrial Electronics, 52, 1, 5-22.

[6] Kolar, J. W., Friedli,T., (2013). The Essence of Three-Phase PFC Rectifier Systems - Part I, IEEE Transactions on Power Electronics, 28, 1, 176-198.

[7] Friedli, T., Hartmann, M., Kolar, J. W., (2014). The Essence of Three-Phase PFC Rectifier Systems - Part II, IEEE Transactions on Power Electronics, 29, 2, 543-560.

[8] Zhang, X., Wang, Q., Burgos, R., Boroyevich, D., (2015). Discontinuous pulse width modulation methods with neutral point voltage balancing for three phase Vienna rectifiers, IEEE Energy Conversion Congress and Exposition (ECCE), 225232.

[9] Kolar, J.W., Zach, F.C., (1997). A novel three-phase utility interface minimizing line current harmonics of high-power telecommunications rectifier modules, IEEE Transactions on Industrial Electronics, 44, 4, 456-467.

[10] Reddy, D., Ramasamy, S., (2018). Design of RBFN Controller Based Boost Type Vienna Rectifier for Grid-Tied Wind Energy Conversion System, IEEE Access, 6, 3167-3175.

[11] Liu, J., Wang, B., Zhao, H., Yang, D., Chen, Z., Yi, B., Li, M., (2018). A wind energy conversion system based on full scale VIENNA rectifier and small-scale
STATCOM, 13th IEEE Conference on Industrial Electronics and Applications (ICIEA), 1431-1436.

[12] Anderson, J. A., Haider, M., Bortis, D., Kolar, J. W., Kasper, M., Deboy, G., (2019). New Synergetic Control of a 20kW Isolated VIENNA Rectifier FrontEnd EV Battery Charger, 20th Workshop on Control and Modeling for Power Electronics (COMPEL), 18.

[13] Yang, X. S., (2008). Nature-Inspired Metaheuristic Algorithms, Luniver Press, Cambridge, U.K.

[14] Yang, X. S., Hosseini, S. S. S., Gandomi, A. H., (2012). Firefly algorithm for solving non-convex economic dispatch problems with valve loading effect, Applied Soft Computing, 12, 1180-1186.

[15] Chandrasekaran, K., Simon, S. P., Padhy, N. P., (2013). Binary real coded firefly algorithm for solving unit commitment problem, Information Sciences, 249, 67-84.

[16] Senthilnath, J., Omkar, S. N., Mani, V., (2011). Clustering using firefly algorithm: performance study, Swarm and Evolutionary Computation, 1, 164171.

[17] Konstantinov, S. V., Baryshnikov, A. A., (2017). Comparative Analysis of Evolutionary Algorithms for the Problem of Parametric Optimization of PID Controllers, Procedia Computer Science, 103, 100107.

[18] Kommula, B. N., Kota, V. R., (2020). Direct instantaneous torque control of Brushless DC motor using firefly Algorithm based fractional order PID controller, Journal of King Saud University Engineering Sciences, 32, 2, 133-140.

[19] Pradhan, P. C., Sahu, R. K., Panda, S., (2016) Firefly algorithm optimized fuzzy PID controller for AGC of multi-area multi-source power systems with UPFC and SMES, Engineering Science and Technology, an International Journal, 19, 1, 338-354.

[20] Lai, R., Wang, F., Burgos, R., Boroyevich, D., Jiang, D., Zhang, D., (2009). Average Modeling and Control Design for Vienna-Type Rectifiers Considering the DC-Link Voltage Balance, IEEE Transactıons on Power Electronics, 24, 11, 2509-2522.

[21] Aiello, G., Cacciato, M., Scarcella, G., Scelba, G., Gennaro, F., Aiello, N., (2019). Real-time emulation of a three-phase Vienna rectifier with DC voltage control and power factor correction, Electrical Engineering, https://doi.org/10.1007/s00202-01900776-y.

[22] Yu F., Liu X., Zhang X., Zhu Z., (2019). Model Predictive Virtual-Flux Control of Three-Phase Vienna Rectifier Without Voltage Sensors, IEEE Access, 7, 169338- 169349.

[23] Li, X., Sun, Y., Wang, H., Su, M., Huang, S., (2018). A Hybrid Control Scheme for Three-Phase Vienna Rectifiers, IEEE Transactions on Power Electronics, 33, 1, 629-640. 
[24] Kedjar, B., Kanaan, H.Y., Al-Haddad, K,. (2014). Vienna Rectifier with Power Quality Added Function, IEEE Transactions on Industrial Electronics, 61, 8, 3847-3856.

[25] Aissaa, O., Moulahouma, S., Colak, I., Babesc, B., Kabacheaa, N., (2017). Design and real time implementation of three-phase three switchesthree levels Vienna rectifier based on intelligent controllers, Applied Soft Computing, 56,158-172.

[26] Dang, C., Tong, X., Yin, J., Huang, J., Xu, Y. (2017). The neutral point-potential and current model predictive control method for Vienna rectifier, Journal of the Franklin Institute, 354, 7605-7623.

[27] Sundareswaran, K., Peddapati, S., Palani, S., (2014). MPPT of PV Systems Under Partial Shaded Conditions Through a Colony of Flashing Fireflies, IEEE Transactions on Energy Conversion, 29, 2, 463-472.
[28] Belkacem, R., Benzıd, R., Bouguechal N. (2017). Multilevel inverter with optimal THD through the firefly algorithm, Archives of Electrical Engineering, 66, 1, 141-154.

[29] Demirdelen, T., (2018). Kuru Tip Transformatör Optimizasyonuna Yeni Bir Yaklaşım: Ateş Böceği Algoritması, Çukurova Üniversitesi Mühendislik Mimarlık Fakültesi Dergisi, 33, 1, 87-96.

[30] Merugumalla, M.K., Navuri, P.K. (2018). PSO and firefly algorithms based control of BLDC motor drive. 2nd International Conference on Inventive Systems and Control (ICISC), 994-999. 